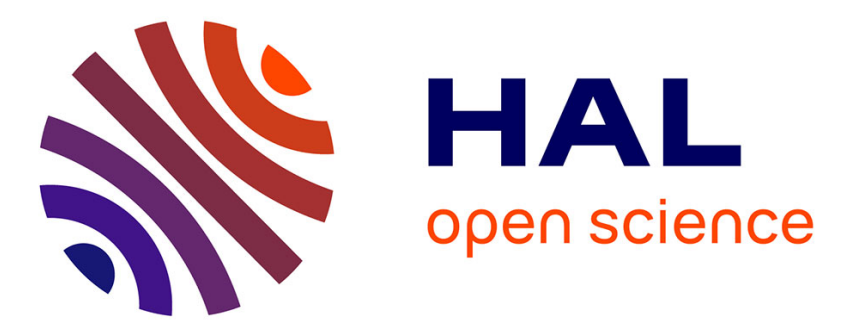

\title{
Prenatal diagnosis of thoracic kidney in the 2nd trimester with delayed manifestation of associated diaphragmatic hernia.
}

Apostolos P. Athanasiadis, Menelaos Zafrakas, Christos Arnaoutoglou, Aikaterini Karavida, Panayiota Papasozomenou, Basil C. Tarlatzis

\section{To cite this version:}

Apostolos P. Athanasiadis, Menelaos Zafrakas, Christos Arnaoutoglou, Aikaterini Karavida, Panayiota Papasozomenou, et al.. Prenatal diagnosis of thoracic kidney in the 2nd trimester with delayed manifestation of associated diaphragmatic hernia.. Journal of Clinical Ultrasound, 2010, 39 (4), pp.221. 10.1002/jcu.20769 . hal-00599774

\section{HAL Id: hal-00599774 https://hal.science/hal-00599774}

Submitted on 11 Jun 2011

HAL is a multi-disciplinary open access archive for the deposit and dissemination of scientific research documents, whether they are published or not. The documents may come from teaching and research institutions in France or abroad, or from public or private research centers.
L'archive ouverte pluridisciplinaire HAL, est destinée au dépôt et à la diffusion de documents scientifiques de niveau recherche, publiés ou non, émanant des établissements d'enseignement et de recherche français ou étrangers, des laboratoires publics ou privés. 
Prenatal diagnosis of thoracic kidney in the 2nd trimester with delayed manifestation of associated diaphragmatic hernia.

\begin{tabular}{|r|l|}
\hline Journal: & Journal of Clinical Ultrasound \\
\hline Miley - Manuscript type: & JCU-10-062.R1 \\
\hline Keywords: & $\begin{array}{l}\text { Prenatal Diagnosis, Ectopic Kidney, Intrathoracic Kidney, Congenital } \\
\text { Diaphragmatic, Ultrasonography }\end{array}$ \\
\hline \multicolumn{2}{|l}{} \\
\hline
\end{tabular}

\section{SCHOLARONE \\ Manuscripts}




\section{TITLE}

Prenatal diagnosis of thoracic kidney in the 2nd trimester with delayed manifestation of associated diaphragmatic hernia.

\section{SHORT TITLE / RUNNING HEAD}

Fetal thoracic kidney with diaphragmatic hernia. 


\begin{abstract}
Ectopic kidney is a rare congenital malformation, caused by renal malpositioning during embryogenesis. We report a rare case of ectopic kidney located in the left hemithorax of a male fetus. The unique features in this case were early sonographic prenatal diagnosis of thoracic kidney at 22 weeks gestation, which was confirmed by fetal MRI, and delayed ultrasound manifestation of associated congenital diaphragmatic hernia at 27 weeks.
\end{abstract}

KEYWORDS: Prenatal Diagnosis; Ectopic Kidney; Intrathoracic Kidney; Congenital Diaphragmatic Hernia; Obstetrics; Ultrasonography 


\section{INTRODUCTION}

Renal ectopia is a rare congenital malformation, caused by malpositioning of the kidney during embryogenesis. Most cases are located in the pelvic and lumbar regions, due to disruption of the normal migration of the kidneys before the $8^{\text {th }}$ embryonic week. Thoracic kidney is extremely rare, located in a higher position, possibly due to a different pathogenetic mechanism. Its prevalence is estimated to be less than $0.01 \%[1,2]$. Rare cases, of acquired thoracic renal ectopia following severe trauma, have been also reported in adults [3]. Congenital thoracic kidney is generally considered to be a sporadic malformation and it is not associated with increased risk of recurrence. Males tend to be affected more often than females (63\% vs. $37 \%$, respectively) and thoracic kidneys are found more often in the left hemithorax than in the right ( $62 \%$ vs. $38 \%$, respectively) $[1,4]$. Extremely rare cases of postnatally diagnosed bilateral congenital thoracic kidneys have been also reported [5]. Thoracic kidneys are classified into four groups: thoracic renal ectopia with 1) closed diaphragm, 2) eventration (i.e. relaxation) of the diaphragm, 3) diaphragmatic hernia, which is subdivided into congenital diaphragmatic defects and acquired hernia, such as Bochdalek hernia and 4) traumatic rupture of the diaphragm $[6,7]$. We report a rare case of thoracic kidney diagnosed prenatally on ultrasound at 22 weeks, with delayed ultrasound manifestation of associated congenital diaphragmatic hernia $(\mathrm{CDH})$ in the $27^{\text {th }}$ week of pregnancy. 


\section{CASE REPORT}

A 25-year-old white woman, G1, was referred for routine anomaly scan at 22 weeks gestation. Ultrasound equipment (Voluson 730 Expert Diamond, GE Healthcare, Kretztechnik, Zipf, Austria) with RAB 4-8 abdominal convex probe $(4-8 \mathrm{MHz})$ was used. Previous obstetrical, medical and family history was unremarkable. The woman was a non-smoker, she did not consume any alcohol during pregnancy and she had never been exposed to drugs or toxins. The dating scan in the first trimester was compatible with dates and the nuchal translucency was normal.

On ultrasound examination at 22 weeks, the left kidney was absent from the ipsilateral renal fossa, while the left hemithorax contained a mass with mixed echogenicity, causing a mediastinal shift to the opposite side (Figure 1). The right kidney was normally located, but its pelvis was dilated to $16 \mathrm{~mm}$. No further malformations were identified at this point. Based on these findings, the initial diagnosis was isolated ectopic thoracic kidney; this was confirmed by TUI, colour flow Doppler, demonstrating the abnormally high origin of left renal artery and 3Dsurface reconstruction scan. Amniocentesis revealed a normal male karyotype (46, $\mathrm{XY}$ ), and fetal echocardiography was also normal. Fetal MRI using 1.5T equipment (Philips Intera Enterprise MRI System, Philips Medical Systems, Best, The Netherland) confirmed diagnosis of isolated intrathoracic kidney; notably there were no signs of diaphragmatic hernia (Figure 2). On follow-up ultrasound at 27 weeks, the appearance of bowel in the thoracic cavity suggested the presence of associated $\mathrm{CDH}$ (Figure 3). Parents were counselled by a paediatric surgeon about neonatal surgical management and decided to continue pregnancy. Prenatal management included serial ultrasound scans in order to monitor fetal growth and assess the fetal heart. 
Elective caesarean section was performed at 34 weeks, due to symptoms of labour (uterine contractions and cervical dilation), in order to facilitate planning of neonatal surgery. Steroids were administered $24 \mathrm{hr}$ prior the delivery and an ex utero intrapartum treatment (EXIT) procedure were used according to our institutional guidelines. A male infant weighing 2,650g was delivered with Apgar scores 7 and 8 at 1 and 5 minutes, respectively. The neonate was initially transferred to the Neonatal Intensive Care Unit (NICU) due to respiratory distress and surgery was performed within two hours from delivery. The herniated viscera, i.e. the left kidney, part of the spleen and part of the small intestine, were carefully re-positioned into the abdominal cavity and the diaphragmatic defect was closed with primary repair. The infant remained postoperatively in the NICU for almost three months, due to respiratory distress and sepsis, and it was discharged in good condition on day 93, weighing 3,680 g. Today, two years after neonatal surgery, the child is in good general health, with normal physical and mental development and without any long term complications. Recent, scintigraphy with Tc-99m MAG-3 and Tc-99m DMSA (Gyroscan T5-NT, Philips Medical Systems, Eindhoven, The Netherlands) showed that both kidneys are adequately functioning. 


\section{DISCUSION}

Thoracic renal ectopia is a very rare congenital malformation. In a study including 15,919 autopsies in children, there was only one case of intrathoracic kidney among 22 cases of renal ectopia [9]. Prenatal diagnosis of ectopic thoracic kidney has been only rarely reported. An extensive search of the contemporary literature revealed only two such cases [2, 8] (MEDLINE; 1970-October 2009; English language; search terms: "Ectopic Kidney", "Intrathoracic Kidney", "Thoracic Kidney" and "Prenatal Diagnosis"); both cases were diagnosed during the third trimester of pregnancy, whereas diagnosis in the present case was set at 22 weeks gestation. It is notable that in the present case diaphragmatic hernia, in contrast to previous cases reported, was not present at the time of prenatal diagnosis. Though a rare anomaly, thoracic kidney should be considered in the differential diagnosis of intrathoracic masses, particularly it should be differentiated from pulmonary sequestration [8].

Underlying diaphragmatic hernia should be always suspected in cases of thoracic renal ectopia, since this condition may manifest later, either in the third trimester, as in the present case, or postnatally, as previously described $[1,10]$. It is well established that fetal MRI provides useful information in cases of $\mathrm{CDH}$ about the herniated viscera [11], as it might demonstrate more accurately hypointense organs. Its main limitation is in cases of a right-sided defect, in which MRI might not be helpful in distinguishing liver from renal parenchyma, as both organs are hypointense. However, it should be noted that in two of the three reported cases [2], including the present case, fetal MRI was carried out and neither revealed the presence of diaphragmatic hernia.

Prenatal management of ectopic kidneys includes amniocentesis for fetal karyotyping, since such malformations might be associated with fetal chromosomal 
anomalies [12, 13]. Furthermore, ectopic kidneys might be associated with other malformations, including rib, cardiovascular, craniofacial, CNS and gastrointestinal anomalies [2, 14, 15], and thus fetal echocardiography and detailed anomaly scan are mandatory. It should be noted however, that there is no consistent pattern of anomalies associated with renal ectopia [16].

Unlike other types of renal ectopia, intrathoracic kidneys usually function normally and very often no medical or surgical treatment is required [5]. Most patients are asymptomatic, and this condition may be discovered incidentally, even in adults [17, 18]. Due to the limited number of prenatally diagnosed cases of ectopic intrathoracic kidney with associated $\mathrm{CDH}$ and despite the fact that post-surgical outcome was favorable in all three reported cases [2, 8], including the one reported here, no firm conclusions can be drawn about elective surgical treatment in the neonatal period. 


\section{REFERENCES}

1. Sozubir S, Demir H, Ekingen G, et al. Ectopic thoracic kidney in a child with congenital diaphragmatic hernia. Eur J Pediatr Surg 2005;15:206.

2. Panda $B$, Rosenberg $V$, Cornfeld $D$, et al. Prenatal diagnosis of ectopic intrathoracic kidney in a fetus with a left diaphragmatic hernia. J Clin Ultrasound 2009;37:47.

3. Suarez S, de Jesus Y. Acquired intrathoracic kidney. P R Health Sci J 1998;17:289.

4. Donat SM, Donat PE. Intrathoracic kidney: a case report with a review of the world literature. J Urol 1988;140:131.

5. Liddell RM, Rosenbaum DM, Blumhagen JD. Delayed radiologic appearance of bilateral thoracic ectopic kidneys. AJR Am J Roentgenol 1989;152:120.

6. N'Guessen G, Stephens FD, Pick J. Congenital superior ectopic (thoracic) kidney. Urology 1984;24:219.

7. Pfister-Goedeke L, Brunier E. Intrathoracic kidney in childhood with special reference to secondary renal transport in Bochdalek's hernia. Helv Paediatr Acta 1979;34:345. 
8. Masturzo B, Kalache KD, Cockell A, et al. Prenatal diagnosis of an ectopic intrathoracic kidney in right-sided congenital diaphragmatic hernia using color Doppler ultrasonography. Ultrasound Obstet Gynecol 2001;18:173.

9. Campbell MF. Renal ectopy. J Urol 1930;24:187-189.

10. Keles $\mathrm{S}$, Artac $\mathrm{H}$, Elmaci $\mathrm{M}$, et al. Late-presenting congenital diaphragmatic hernia associated with ectopic thoracic kidney. Eur J Pediatr 2006;165:571.

11. Hubbard AM, Crombleholme TM, Adzick NS, et al. Prenatal MRI evaluation of congenital diaphragmatic hernia. Am J Perinatol 1999;16:407.

12. Navarro A, Jimenez J, Rios $T$, et al. Unusual cause of lung and renal disease in a baby with trisomy 21. Pediatr Pulmonol 2005;40:173.

13. Chu IW, Yeh SJ, Lin YC. Intrathoracic kidney in a case of trisomy 18. Turk J Pediatr 2008;50:176.

14. Sumner TE, Volberg FM, Smolen PM. Intrathoracic kidney--diagnosis by ultrasound. Pediatr Radiol 1982;12:78.

15. Pelizzo G, Lembo MA, Franchella A, et al. Gastric volvulus associated with congenital diaphragmatic hernia, wandering spleen, and intrathoracic left kidney: CT findings. Abdom Imaging 2001;26:306. 
16. Hampton LJ, Borden TA. Ureteropelvic junction obstruction in a thoracic kidney treated by dismembered pyeloplasty. Urology 2002;60:164.

17. Singh P, Vijjan V, Gupta M, et al. Percutaneous nephrolithotomy of a staghorn stone in thoracic ectopic kidney. Int J Urol 2007;14:558.

18. Sundaram V, Vidhyashree SA, Pratap B, et al. A male patient with right-sided thoracic kidney, diabetes mellitus, hearing loss and renal dysfunction. Int Urol Nephrol 2007;39:959-62. 


\section{FIGURE LEGENDS}

Figure 1: Transverse and sagittal sections of the fetal thorax on prenatal ultrasound at 22 weeks, demonstrating the ectopic kidney $(K)$ in the left hemithorax, compressed left lung (L), shift of the heart $(H)$ to the right, diaphragm (D) and absence of viscera in the thorax.

Figure 2: Sagittal section of the fetal thorax with Magnetic Resonance Imaging demonstrating the ectopic kidney (arrow) and the absence of $\mathrm{CDH}$.

Figure 3: Transverse section of the fetal thorax on prenatal ultrasound at 27 weeks, demonstrating the ectopic kidney $(K)$ and bowel $(B)$ in the left hemithorax, compressed left lung $(\mathrm{L})$ and shift of the heart $(\mathrm{H})$ to the right. 


\section{TITLE}

Prenatal diagnosis of thoracic kidney in the 2nd trimester with delayed manifestation of associated diaphragmatic hernia.

\section{SHORT TITLE / RUNNING HEAD}

Fetal thoracic kidney with diaphragmatic hernia. 


\begin{abstract}
Ectopic kidney is a rare congenital malformation, caused by renal malpositioning during embryogenesis. We report a rare case of ectopic kidney located in the left hemithorax of a male fetus. The unique features in this case were early sonographic prenatal diagnosis of thoracic kidney at 22 weeks gestation, which was confirmed by fetal MRI, and delayed ultrasound manifestation of associated congenital diaphragmatic hernia at 27 weeks. This is the first case of prenatal diagnosis of ectopic thoracic kidney in the second trimester of pregnancy.
\end{abstract}

KEYWORDS: Prenatal Diagnosis; Ectopic Kidney; Intrathoracic Kidney; Renal Ectopy; Congenital Diaphragmatic Hernia; Obstetrics; Ultrasonography 


\section{INTRODUCTION}

Renal ectopia is a rare congenital malformation, caused by malpositioning of the kidney during embryogenesis. Most cases are located in the pelvic and lumbar regions, due to disruption of the normal migration of the kidneys before the $8^{\text {th }}$ embryonic week. Thoracic kidney is extremely rare, located in a higher position, possibly due to a different pathogenetic mechanism. Its prevalence is estimated to be less than $0.01 \%[1,2]$. Rare cases, of acquired thoracic renal ectopia following severe trauma, have been also reported in adults [3]. Congenital thoracic kidney is generally considered to be a sporadic malformation and it is not associated with increased risk of recurrence. Males tend to be affected more often than females (63\% vs. $37 \%$, respectively) and thoracic kidneys are found more often in the left hemithorax than in the right $(62 \%$ vs. $38 \%$, respectively) $[1,4]$. Extremely rare cases of postnatally diagnosed bilateral congenital thoracic kidneys have been also reported [5]. Thoracic kidneys are classified into four groups: thoracic renal ectopia with 1) closed diaphragm, 2) eventration (i.e. relaxation) of the diaphragm, 3) diaphragmatic hernia, which is subdivided into congenital diaphragmatic defects and acquired hernia, such as Bochdalek hernia and 4) traumatic rupture of the diaphragm $[6,7]$. We report a rare case of thoracic kidney diagnosed prenatally on ultrasound at 22 weeks, with delayed ultrasound manifestation of associated congenital diaphragmatic hernia $(\mathrm{CDH})$ in the $27^{\text {th }}$ week of pregnancy. 


\section{CASE REPORT}

A 25-year-old white woman, G1, was referred for routine anomaly scan at 22 weeks gestation. Ultrasound equipment (Voluson 730 Expert Diamond, GE Healthcare, Kretztechnik, Zipf, Austria) with RAB 4-8 abdominal convex probe (4-8MHz) was used. Previous obstetrical, medical and family history was unremarkable. The woman was a non-smoker, she did not consume any alcohol during pregnancy and she had never been exposed to drugs or toxins. The dating scan in the first trimester was compatible with dates and the nuchal translucency was normal.

On ultrasound examination at 22 weeks, the left kidney was absent from the ipsilateral renal fossa, while the left hemithorax contained a mass with mixed echogenicity, causing a mediastinal shift to the opposite side (Figure 1). The right kidney was normally located, but its pelvis was dilated to $16 \mathrm{~mm}$. No further malformations were identified at this point. Based on these findings, the initial diagnosis was isolated ectopic thoracic kidney; this was confirmed by TUI, colour flow Doppler, demonstrating the abnormally high origin of left renal artery and 3Dsurface reconstruction scan. Amniocentesis revealed a normal male karyotype (46, $\mathrm{XY}$ ), and fetal echocardiography was also normal. Fetal MRI using 1.5T equipment (Philips Intera Enterprise MRI System, Philips Medical Systems, Best, The Netherland) confirmed diagnosis of isolated intrathoracic kidney; notably there were no signs of diaphragmatic hernia (Figure 2). On follow-up ultrasound at 27 weeks, the appearance of bowel in the thoracic cavity suggested the presence of associated $\mathrm{CDH}$ (Figure 3). Parents were counselled by a paediatric surgeon about neonatal surgical management and decided to continue pregnancy. Prenatal management included serial ultrasound scans in order to monitor fetal growth and assess the fetal heart. 
Elective caesarean section was performed at 34 weeks, due to symptoms of labour (uterine contractions and cervical dilation), in order to facilitate planning of neonatal surgery. Steroids were administered $24 \mathrm{hr}$ prior the delivery and an ex utero intrapartum treatment (EXIT) procedure were used according to our institutional guidelines. A male infant weighing 2,650g was delivered with Apgar scores 7 and 8 at 1 and 5 minutes, respectively. The neonate was initially transferred to the Neonatal Intensive Care Unit (NICU) due to respiratory distress and surgery was performed within two hours from delivery. The herniated viscera, i.e. the left kidney, part of the spleen and part of the small intestine, were carefully re-positioned into the abdominal cavity and the diaphragmatic defect was closed with primary repair. The infant remained postoperatively in the NICU for almost three months, due to respiratory distress and sepsis, and it was discharged in good condition on day 93, weighing 3,680 g. Today, two years after neonatal surgery, the child is in good general health, with normal physical and mental development and without any long term complications. Recent, scintigraphy with Tc-99m MAG-3 and Tc-99m DMSA (Gyroscan T5-NT, Philips Medical Systems, Eindhoven, The Netherlands) showed that both kidneys are adequately functioning. 


\section{DISCUSION}

Thoracic renal ectopia is a very rare congenital malformation. In a study including 15,919 autopsies in children, there was only one case of intrathoracic kidney among 22 cases of renal ectopia [8,9]. Prenatal diagnosis of ectopic thoracic kidney has been only rarely reported. An extensive search of the contemporary literature revealed only two such cases [2, 8] (MEDLINE; 1970-October 2009; English language; search terms: "Ectopic Kidney", "Intrathoracic Kidney", "Thoracic Kidney" and "Prenatal Diagnosis"); both cases were diagnosed during the third trimester of pregnancy, whereas diagnosis in the present case was set at 22 weeks gestation. It is notable that in the present case diaphragmatic hernia, in contrast to previous cases reported, was not present at the time of prenatal diagnosis. Though a rare anomaly, thoracic kidney should be considered in the differential diagnosis of intrathoracic masses, particularly it should be differentiated from pulmonary sequestration [8].

Underlying diaphragmatic hernia should be always suspected in cases of thoracic renal ectopia, since this condition may manifest later, either in the third trimester, as in the present case, or postnatally, as previously described $[1,10]$. It is well established that fetal MRI provides useful information in cases of $\mathrm{CDH}$ about the herniated viscera [11], as it might demonstrate more accurately hypointense organs. Its main limitation is in cases of a right-sided defect, in which MRI might not be helpful in distinguishing liver from renal parenchyma, as both organs are hypointense. However, it should be noted that in all three reported cases of prenatally diagnosed thoracic kidney $[1,8]$, including the present case, fetal MRI did not reveal the presence of diaphragmatic hernia. However, it should be noted that in 
two of the three reported cases [2], including the present case, fetal MRI was carried out and neither revealed the presence of diaphragmatic hernia.

Prenatal management of ectopic kidneys includes amniocentesis for fetal karyotyping, since such malformations might be associated with fetal chromosomal anomalies [12, 13]. Furthermore, ectopic kidneys might be associated with other malformations, including rib, cardiovascular, craniofacial, CNS and gastrointestinal anomalies [2, 14, 15], and thus fetal echocardiography and detailed anomaly scan are mandatory. It should be noted however, that there is no consistent pattern of anomalies associated with renal ectopia [16].

Unlike other types of renal ectopia, intrathoracic kidneys usually function normally and very often no medical or surgical treatment is required [5]. Most patients are asymptomatic, and this condition may be discovered incidentally, even in adults [17, 18]. Due to the limited number of prenatally diagnosed cases of ectopic intrathoracic kidney with associated $\mathrm{CDH}$ and despite the fact that post-surgical outcome was favorable in all three reported cases $[2,8]$, including the one reported here, no firm conclusions can be drawn about elective surgical treatment in the neonatal period.

In conclusion, this is a prenatally diagnosed thoracic kidney in the second trimester of pregnancy, with delayed ultrasound manifestation of an associated congenital diaphragmatic hernia. 


\section{REFERENCES}

1. Sozubir S, Demir H, Ekingen G, et al. Ectopic thoracic kidney in a child with congenital diaphragmatic hernia. Eur J Pediatr Surg 2005;15:206.

2. Panda $B$, Rosenberg V, Cornfeld $D$, et al. Prenatal diagnosis of ectopic intrathoracic kidney in a fetus with a left diaphragmatic hernia. J Clin Ultrasound 2009;37:47.

3. Suarez S, de Jesus Y. Acquired intrathoracic kidney. P R Health Sci J 1998;17:289.

4. Donat SM, Donat PE. Intrathoracic kidney: a case report with a review of the world literature. J Urol 1988;140:131.

5. Liddell RM, Rosenbaum DM, Blumhagen JD. Delayed radiologic appearance of bilateral thoracic ectopic kidneys. AJR Am J Roentgenol 1989;152:120.

6. N'Guessen G, Stephens FD, Pick J. Congenital superior ectopic (thoracic) kidney. Urology 1984;24:219.

7. Pfister-Goedeke L, Brunier E. Intrathoracic kidney in childhood with special reference to secondary renal transport in Bochdalek's hernia. Helv Paediatr Acta $1979 ; 34: 345$. 
8. Masturzo B, Kalache KD, Cockell A, et al. Prenatal diagnosis of an ectopic intrathoracic kidney in right-sided congenital diaphragmatic hernia using color Doppler ultrasonography. Ultrasound Obstet Gynecol 2001;18:173.

9. Campbell MF. Renal ectopy. J Urol 1930;24:187-189.

10. Keles S, Artac $\mathrm{H}$, Elmaci $\mathrm{M}$, et al. Late-presenting congenital diaphragmatic hernia associated with ectopic thoracic kidney. Eur J Pediatr 2006;165:571.

11. Hubbard AM, Crombleholme TM, Adzick NS, et al. Prenatal MRI evaluation of congenital diaphragmatic hernia. Am J Perinatol 1999;16:407.

12. Navarro A, Jimenez J, Rios $T$, et al. Unusual cause of lung and renal disease in a baby with trisomy 21. Pediatr Pulmonol 2005;40:173.

13. Chu IW, Yeh SJ, Lin YC. Intrathoracic kidney in a case of trisomy 18. Turk J Pediatr 2008;50:176.

14.Sumner TE, Volberg FM, Smolen PM. Intrathoracic kidney--diagnosis by ultrasound. Pediatr Radiol 1982;12:78.

15. Pelizzo G, Lembo MA, Franchella A, et al. Gastric volvulus associated with congenital diaphragmatic hernia, wandering spleen, and intrathoracic left kidney: CT findings. Abdom Imaging 2001;26:306. 
16. Hampton LJ, Borden TA. Ureteropelvic junction obstruction in a thoracic kidney treated by dismembered pyeloplasty. Urology 2002;60:164.

17. Singh P, Vijjan V, Gupta M, et al. Percutaneous nephrolithotomy of a staghorn stone in thoracic ectopic kidney. Int J Urol 2007;14:558.

18. Sundaram V, Vidhyashree SA, Pratap B, et al. A male patient with right-sided thoracic kidney, diabetes mellitus, hearing loss and renal dysfunction. Int Urol Nephrol 2007;39:959-62. 


\section{FIGURE LEGENDS}

Figure 1: Transverse and sagittal sections of the fetal thorax on prenatal ultrasound at 22 weeks, demonstrating the ectopic kidney $(\mathrm{K})$ in the left hemithorax, compressed left lung $(\mathrm{L})$, shift of the heart $(\mathrm{H})$ to the right, diaphragm (D) and absence of viscera in the thorax.

Figure 2: Sagittal section of the fetal thorax with Magnetic Resonance Imaging demonstrating the ectopic kidney (arrow) and the absence of $\mathrm{CDH}$.

Figure 3: Transverse section of the fetal thorax on prenatal ultrasound at 27 weeks, demonstrating the ectopic kidney $(\mathrm{K})$ and bowel $(\mathrm{B})$ in the left hemithorax, compressed left lung $(\mathrm{L})$ and shift of the heart $(\mathrm{H})$ to the right. 
Figure 1 Transverse and sagittal sections of the fetal thorax on prenatal ultrasound at 22 weeks, demonstrating the ectopic kidney $(K)$ in the left hemithorax, compressed left lung $(L)$, shift of the heart $(H)$ to the right, diaphragm (D) and absence of viscera in the thorax.

\section{$251 \times 141 \mathrm{~mm}(300 \times 300$ DPI $)$}




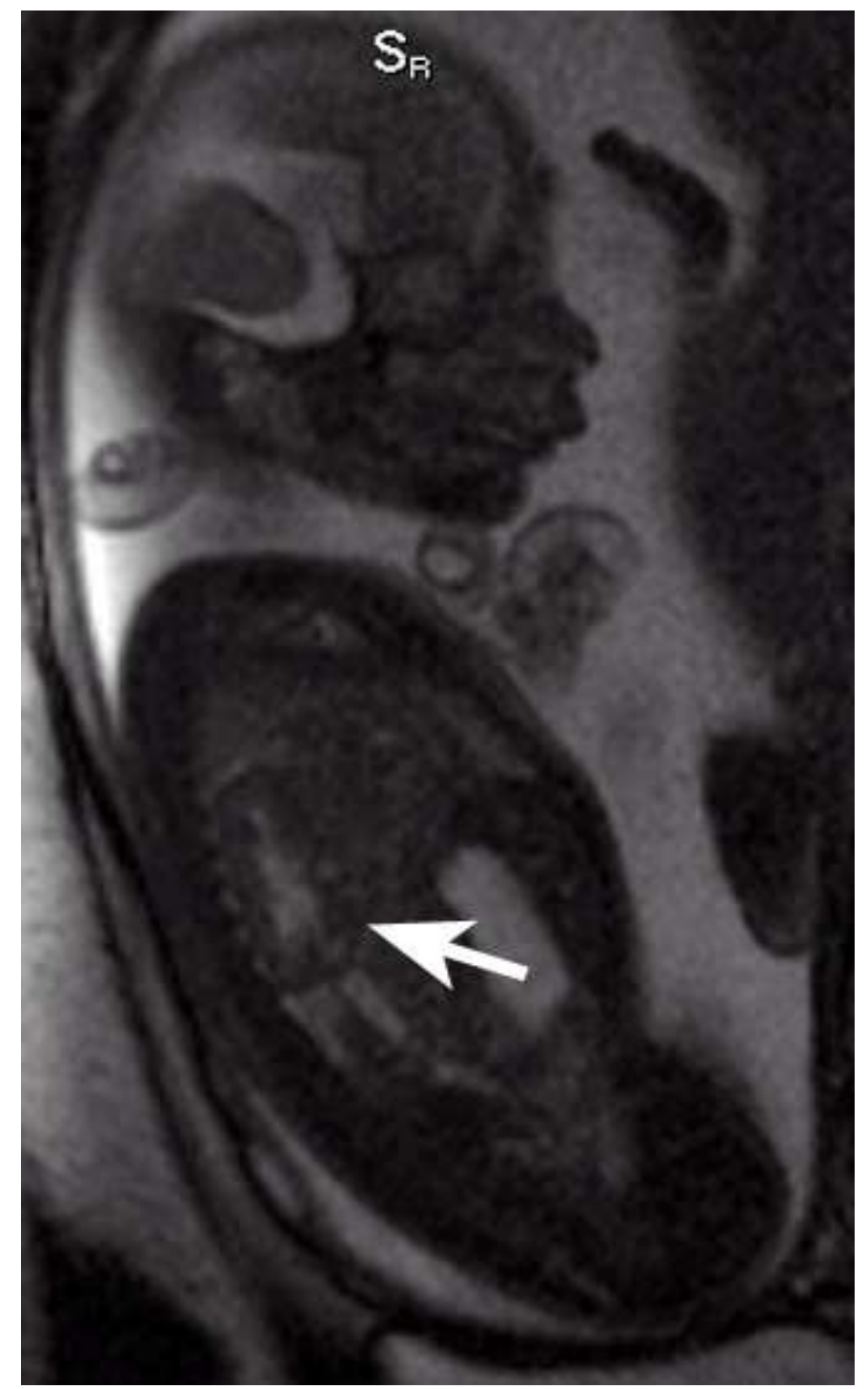

Figure 2 Sagittal section of the fetal thorax with Magnetic Resonance Imaging demonstrating the ectopic kidney (arrow) and the absence of $\mathrm{CDH}$. $118 \times 195 \mathrm{~mm}(72 \times 72 \mathrm{DPI})$ 
Figure 3 Transverse section of the fetal thorax on prenatal ultrasound at 27 weeks, demonstrating the ectopic kidney $(K)$ and bowel $(B)$ in the left hemithorax, compressed left lung $(L)$ and shift of the heart $(\mathrm{H})$ to the right. $165 \times 151 \mathrm{~mm}(300 \times 300$ DPI $)$ 